\title{
Paclobutrazol em oliveira submetida a diferentes regimes hídricos
}

\section{Paclobutrazol in olive trees under different water levels}

\author{
Adelson Francisco de Oliveira ${ }^{1^{*}}$; Maria do Céu Monteiro da Cruz ${ }^{2}$; \\ Dili Luiza de Oliveira ${ }^{3}$; Hugo Adelande de Mesquita ${ }^{4}$
}

\section{Resumo}

A adaptação de cultivares de oliveiras às condições climáticas de algumas regiões no Brasil tem despertado o interesse de produtores para o seu cultivo. Entretanto, para a expansão das áreas produtoras torna-se necessário estudar os fatores que interferem no crescimento e na reprodução da espécie. Assim, o presente trabalho foi realizado com o objetivo de avaliar o crescimento vegetativo e o comportamento reprodutivo da oliveira submetida à aplicação de paclobutrazol (PBZ) sob condições diferentes de disponibilidade hídrica (DH). Foi utilizado o esquema fatorial 4 × 2 × 2, em blocos casualizados, com três repetições e duas plantas por parcela. Plantas da variedade Arbequina, com três anos, foram submetidas à aplicação de quatro doses de $\operatorname{PBZ}(0,0 ; 2,0 ; 4,0$ e 8,0 g por planta), duas formas de aplicação (no solo e pulverização foliar) e dois regimes de DH (com e sem restrição hídrica). O PBZ foi efetivo para retardar o crescimento das plantas em ambas as formas aplicadas. Quando o PBZ foi aplicado no solo sua atuação na planta ocorreu de forma lenta. O déficit hídrico favoreceu a ação do PBZ na planta quando aplicado via foliar e retardou quando a aplicação foi realizada no solo. Não foi observado o florescimento da oliveira com a aplicação de paclobutrazol e déficit hídrico nas condições estudadas.

Palavras-chave: Olea europaea L., déficit hídrico, indução floral, manejo

\begin{abstract}
Adaptation of olive cultivars to climatic conditions of some regions in Brazil has attracted the interest of producers for their cultivation. However, for the expansion of production areas it is necessary to study the factors that influence growth and reproduction of the species. The aim of this research was to evaluate the vegetative growth of olive trees and their reproductive performance when submitted to paclobutrazol application (PBZ) under different conditions of water availability (WA). The experiment was set in $4 \times 2 \times 2$ factorial scheme, with randomized blocks, three replications, and two plants per plot. Three-year-old cv. Arbequina olive trees were submitted to four PBZ doses $(0.0 ; 2.0 ; 4.0$ and $8.0 \mathrm{~g}$ per plant), two application forms (in soil and foliar) and two levels of WA. PBZ was effective to slow the plants growth in both forms applied. When PBZ was applied in the soil its action in the plants was slow. Water stress favored the paclobutrazol action in plants when applied in leaves but when the PBZ was applied to the soil its performance was slow in the plants. In the studied conditions there was no olive tree flowering with Paclobutrazol and water deficit.
\end{abstract}

Key words: Olea europaea L., water deficit, floral induction, management

\footnotetext{
${ }^{1}$ Eng $^{\circ}$ Agro $^{\circ}$, D.Sc. Pesquisador da EPAMIG U.R. SM, Empresa de Pesquisa Agropecuária de Minas Gerais. Bolsista FAPEMIG, C. P. 176, CEP 37200-000 Lavras, MG. E-mail: adelson@epamig.ufla.br

${ }^{2}$ Engr Agr $^{\mathrm{a}}$, Pós-D.Sc. Prof ${ }^{\mathrm{a}}$. do Dept ${ }^{\circ}$. de Agronomia da Universidade Federal dos Vales do Jequitinhonha e Mucuri, UFVJM, Campus JK, Diamantina, MG. E-mail: mariceu@ufvjm.edu.br

${ }^{3}$ D.Sc. Pós-Doutoranda da EPAMIG U.R. SM. Bolsista FAPEMIG, Lavras, MG. E-mail: dililuiza@gmail.com

${ }^{4}$ Eng $^{\text {O Agro }}{ }^{\circ}$ D.Sc. Pesquisador da EPAMIG U.R. SM. Lavras, MG. E-mail: adelande@epamig.ufla.br

* Autor para correspondência
} 


\section{Introdução}

O cultivo de oliveiras no Brasil tem ocorrido principalmente nas regiões Sul e Sudeste do país, caracterizadas por clima temperado em função da altitude, apta ao cultivo de oliveiras pela ocorrência da baixas temperaturas durante o inverno.

Nos últimos anos, a pesquisa possibilitou a identificação de variedades promissoras para a região Sul do Estado de Minas Gerais e recentemente foram selecionadas variedades com menor exigência em frio, a exemplo da 'Arbequina' que se tornou alternativa para o cultivo em outras regiões. A cultivar apresenta vigor reduzido, autocompatível, precoce quanto ao início da produção e época de floração intermédia.

Entretanto, os plantios em condições de clima subtropical apresentam maior crescimento vegetativo das plantas quando comparado as plantas de clima mediterrâneo, em detrimento a produção de frutos. Para isso, a utilização de práticas de manejo capazes de retardar o crescimento da planta e induzir a floração, tem sido aplicada.

Em outras espécies frutíferas, o estresse hídrico parece ser o principal fator promotor da floração nas regiões de clima tropical. O efeito do déficit hídrico pode estar diretamente relacionado com a quebra da dormência das gemas e/ou com a indução floral (DAVENPORT, 1990). A utilização do déficit hídrico para induzir a floração tem sido relacionada com a redução do crescimento do sistema radicular, uma vez que o menor crescimento de raízes pode afetar a síntese hormonal, alterando o seu balanço na planta (JACKSON, 1993).

A paralisação e, ou a redução do sistema radicular causado pela restrição hídrica tem favorecido o florescimento devido à baixa síntese de giberelinas, sendo estas entre todos os hormônios, que demonstraram influência direta sobre a floração (KRAJEWSKI; RABE, 1995). Uma vez que a produção de giberelinas ocorre, principalmente, nas raízes, a utilização de práticas que proporcione o menor crescimento do sistema radicular influenciará na produção deste hormônio.
A utilização de fitorreguladores que exercem efeitos semelhantes ao da restrição hídrica, capazes de retardar o crescimento e inibir a síntese de giberelinas tem despertado interesse na indução de florescimento. Fitorreguladores como o Etil-trinexapac tem retardado o crescimento de plantas, devido à capacidade de reduzir os níveis endógenos da forma ativa de giberelina ácida GA1 (LEITE; CRUSCIOL; SILVA, 2011). Entretanto, o paclobutrazol (PBZ) é um fitorregulador ativo na redução do crescimento de plantas lenhosas (FLETCHER et al., 2000), atuando na inibição da síntese de giberelinas (RADEMACHER, 2000). O PBZ tem se mostrado efetivo quando aplicado via foliar (INTRIERI; SILVESTRONI; PONI, 1986), em concentrações de 500 a $2000 \mathrm{mg} \mathrm{L}^{-1}$ (SANTOS et al., 2004), e via solo (REYNOLDS; WARDLE, 1990), em doses de 200 a 1200 mg planta-1 (CRUZ et al., 2009).

As giberelinas endógenas exercem influenciam na inibição do florescimento, assim acredita-se na hipótese de que a aplicação de fitorreguladores e a baixa disponibilidade hídrica, capazes de inibir a síntese de giberelinas, podem promover o florescimento em qualquer época, principalmente em regiões de clima tropical onde não ocorrem e baixas temperaturas durante o inverno (DAVENPORT, 1990). Entretanto, não existem relatos sobre a efetividade do PBZ em induzir o florescimento nas espécies lenhosas, quando aplicado em períodos em que as condições ambientais não são indutivas ao florescimento, ou seja, sem a ocorrência de estresse hídrico ou baixas temperaturas.

A aplicação de PBZ e restrição hídrica também influenciam sobre outras características das plantas, além da redução no crescimento. Delgado, Rodriguez e Casamayor (1995) constataram aumento no teor de clorofila das folhas em função da aplicação do PBZ. Enquanto na condição de restrição de disponibilidade hídrica, ocorre redução no potencial hídrico foliar (AHMED; BEN ROUINA; BOUKHRISS, 2007; ROUSSEAUX; BENEDETTI; SEARLES, 2008), decréscimo 
dos teores de clorofila devido à redução da taxa fotossintética (GUERFEL et al., 2009).

Desta forma, há necessidade de definir práticas de manejo que possam auxiliar o cultivo em regiões com menor ocorrência de frio. Pois a existência de informações e o entendimento sobre os efeitos advindos das modificações na região de cultivo, especialmente pela aplicação de restrição hídrica e fitorreguladores sobre as oliveiras ainda é incipiente. Desta forma, este trabalho foirealizado com o objetivo de estudar o crescimento vegetativo e reprodutivo da oliveira (Olea europaea L.) submetida à aplicação de paclobutrazol (PBZ), sob condições de restrição hídrica e irrigada, na região do médio Jequitinhonha, norte do Estado de Minas Gerais.

\section{Material e Métodos}

O trabalho foi realizado na Fazenda Experimental de Acauã, localizada na Região do médio Jequitinhonha, Estado de Minas Gerais, no município de Leme do Prado, com altitude média de 822 metros, a 170 07'40" de Latitude Sul e Longitude de 420 46' 23" Oeste. O solo desta região é classificado como Latossolo Vermelho. As médias mensais das temperaturas mínima e máxima, precipitação e umidade relativa observados ao longo da execução do experimento estão descritos na Figura 1.

Figura 1. Médias mensais das temperaturas, mínima e máxima, umidade relativa e precipitação que ocorreram na região durante o período experimental. Fonte: Estação meteorológica da EPAMIG de Leme do Prado, MG.
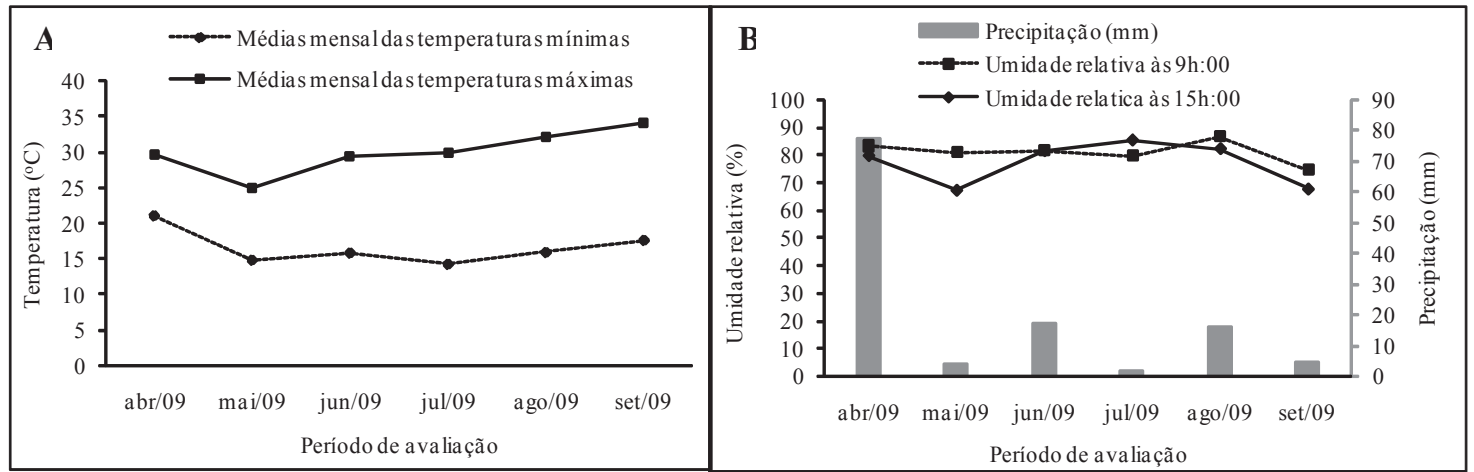

Fonte: Elaboração dos autores.

As plantas utilizadas foram da cultivar Arbequina, com três anos de idade, considerada pouco exigente em frio hibernal, obtidas a partir de enraizamento, plantadas no espaçamento de $6,0 \mathrm{~m}$ entre linhas e 3,0 m entre plantas. As adubações foram realizadas de acordo com análises foliares e de solo e os tratos culturais, e controle de pragas foram realizados conforme as recomendações técnicas para a cultura (MESQUITA et al., 2006).

O delineamento experimental utilizado foi em blocos casualizados, seguindo esquema fatorial
$4 \times 2 \times 2$. Foram utilizadas quatro doses de PBZ $(0,0 ; 2,0 ; 4,0$ e 8,0 g por planta), em duas formas de aplicação (via solo e pulverização foliar) e dois regimes hídricos, (com e sem restrição hídrica), com parcelas subdividas no tempo, referente às avaliações realizadas durante o período de restrição hídrica (RH), aos 60 e 120 dias após a aplicação do PBZ. Cada unidade experimental foi composta de duas plantas.

Para a aplicação do PBZ foi utilizado o produto comercial Cultar ${ }^{\circledR}$, concentrado solúvel contendo 
$250 \mathrm{~g} \mathrm{~L}^{-1}$ do PBZ. A aplicação no solo, as doses estabelecidas em cada tratamento foram dissolvidas em 10 litros de água antes de serem aplicadas nas plantas. Para aplicação foliar as doses foram preparadas nas concentrações de 0, 200, 400 e 800 $\mathrm{mg} \mathrm{L}^{-1}$ de PBZ, utilizando volume médio de 1,5 de solução por planta A época de aplicação do PBZ de ambas as formas aplicadas foi feita uma única vez no mês de abril, quando as plantas alteram a condição fisiológica nos tecidos para a recepção dos fatores externos para a indução floral.

Metade das plantas foi submetida à condição de restrição hídrica (RH), mediante a suspensão da irrigação, e as demais foram irrigadas (sem
RH) duas vezes por semana, de modo a manter a umidade no solo na capacidade de campo, durante todo o período experimental. Para monitorar o potencial hídrico no solo (Figura 2) foram instalados tensiômetros analógicos, dois na profundidade de $0,25 \mathrm{~m}$ na área sem $\mathrm{RH}$ e dois nas profundidades de $0,2 \mathrm{~m}$ e $0,4 \mathrm{~m}$ na área submetida à $\mathrm{RH}$, visto que nessa área o déficit hídrico foi maior, alcançando maiores profundidades, diferente da área que foi irrigada. Os tensiômetros foram instalados próximo ao caule, cerca de $0,4 \mathrm{~m}$ e as leituras realizadas periodicamente durante o experimento, duas vezes por semana, no período da manhã. Após o período de RH, as irrigações foram retomadas, mantendo-se a umidade do solo próxima da capacidade de campo.

Figura 2. Potencial hídrico $\left(\psi_{\mathrm{w}}\right)$ do solo na profundidade $0,25 \mathrm{~m}$ na área irrigada (A) e nas profundidades de $0,2 \mathrm{e}$ $0,4 \mathrm{~m}$ na área submetida à restrição hídrica, plantadas com oliveiras (Olea europaea L.) em função do período de avaliação.
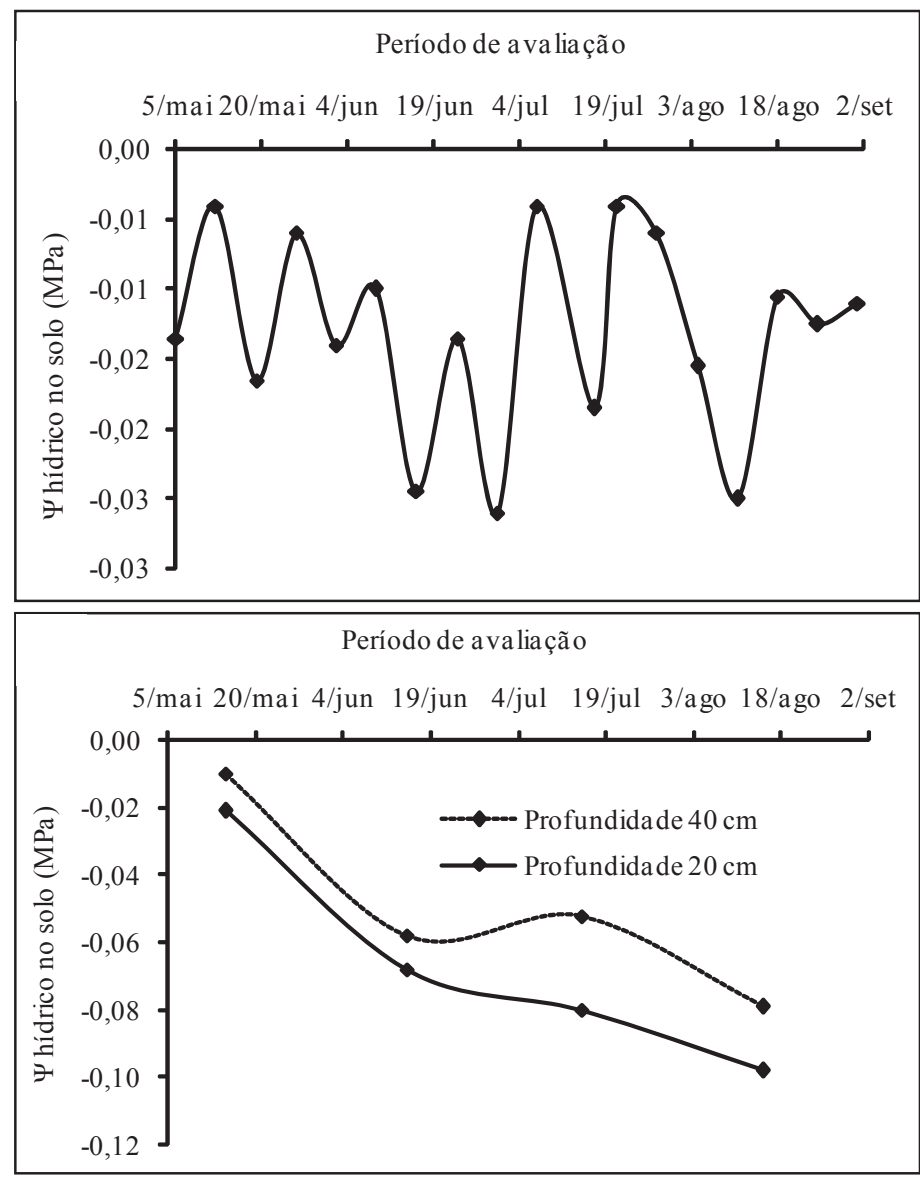

Fonte: Elaboração dos autores. 
Durante o período de $\mathrm{RH}$, de abril a agosto, o potencial hídrico foi monitorado em folhas maduras, retiradas da parte mediana das plantas, entre 5h:00 e 5h:30 da manhã. As determinações foram realizadas na zona de abscisão do pecíolo da lâmina foliar, imediatamente após a remoção das folhas, usandose a câmara de pressão, modelo 3000, Soilmoisture Equipment Corporation, Santa Bárbara, EUA, sendo as leituras expressas em MPa.

Aos 0, 60 e 120 dias após a aplicação do PBZ foi feita a caracterização das plantas quanto à altura das plantas e o diâmetro do caule para determinar o crescimento das plantas após a aplicação dos tratamentos, calculado a partir da diferença entre a altura e diâmetro do caule determinados nas diferentes épocas. A altura das plantas foi determinada a partir da distância entre a zona do colo junto ao solo até o ápice do ramo mais alto da copa, e o diâmetro do caule foi determinado a $20 \mathrm{~cm}$ a partir do solo.

Nas brotações emitidas a partir da aplicação do PBZ, aos 60 e 120 dias, foi realizada a avaliação do comprimento de entrenós para determinar o efeito dos tratamentos sobre o crescimento vegetativo das plantas. Aos 120 dias após a aplicação dos tratamentos, PBZ e RH, o teor relativo de clorofila foi determinado utilizando um clorofilômetro SPAD-502, Minolta Japão. Em cada planta, foram selecionadas folhas maduras e completamente expandidas. As leituras foram feitas na face adaxial das folhas, evitando-se a nervura central da folha.

A avaliação do comportamento reprodutivo não foi realizada porque as emissões de inflorescências não foram registradas nas condições estudadas. Dessa forma, apenas os dados referente ao crescimento das plantas foram submetidos à análise de variância e regressão polinomial, sendo a escolha dos modelos baseada nos testes de significância dos parâmetros e do coeficiente de regressão, utilizando-se o teste 't' a 5\% de probabilidade de erro. Os tratamentos de natureza qualitativa foram comparados pelo teste $\mathrm{F}(\mathrm{p}<0,05)$.

\section{Resultados e Discussão}

Quando o PBZ foi aplicado via foliar, houve efeito do PBZ sobre o comprimento de entrenós e interação entre as concentrações PBZ e a disponibilidade hídrica e das concentrações de PBZ e época sobre o crescimento em altura e diâmetro do caule. Para a aplicação do PBZ via solo, foi observada interação entre doses, disponibilidade hídrica e época para o crescimento em altura e diâmetro do caule e diferenças sobre o comprimento de entrenós nas diferentes épocas. Independente da forma de aplicação do PBZ foi observada diferença no teor relativo de clorofila (SPAD) em função das doses de PBZ e interação entre época e disponibilidade hídrica para o potencial hídrico foliar $\left(\psi_{\mathrm{w}}\right)$.

O PBZ aplicado via foliar retardou o crescimento em altura e o diâmetro do caule das plantas, indiferentemente do regime hídrico avaliado. Foi observado decréscimo de $21,1 \%$ e $20,2 \%$ no crescimento em altura e de $14,5 \%$ e $17,7 \%$ no diâmetro do caule das plantas que foram irrigadas e submetidas à restrição hídrica, respectivamente, com a aplicação de $800 \mathrm{mg} \mathrm{L}^{-1}$ em relação as plantas que não receberam a aplicação do PBZ (Figuras 3A e 3B). Este comportamento demonstra a efetividade do PBZ em retardar o crescimento vegetativo, assim como abordado por Fletcher et al. (2000). 
Figura 3. Crescimento da altura de plantas (A) e diâmetro do caule (B) em oliveira (Olea europaea L.), irrigada (sem $\mathrm{RH}$ ) e submetida à restrição hídrica (com RH), após a aplicação de paclobutrazol (PBZ) via foliar. (As barras sobre as medias observadas indicam o desvio-padrão).
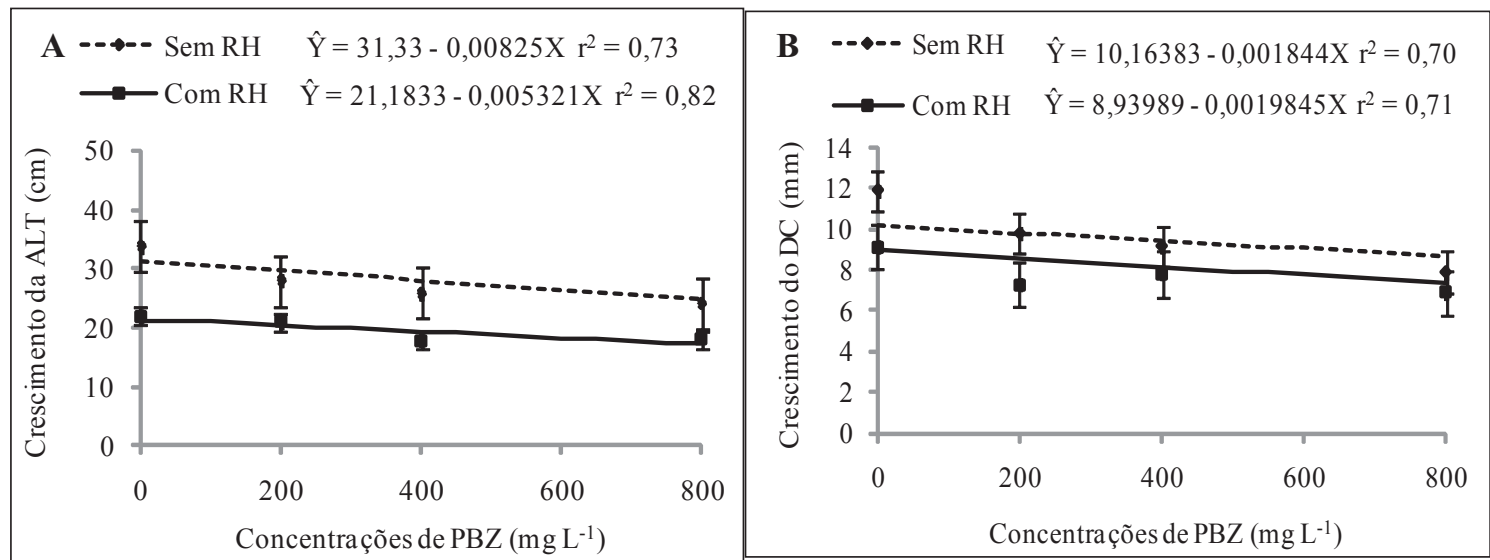

Fonte: Elaboração dos autores.

Quando foi comparado o desenvolvimento das plantas submetidas à restrição hídrica com aquelas irrigadas, observou-se que o crescimento das plantas foi menor sob condição de baixa disponibilidade hídrica no solo (Figuras 3A e 3B). Esse resultado sugere que a baixa disponibilidade de água para as plantas interfere no seu desenvolvimento em decorrência da alteração na produção e transporte de fitorreguladores (GOLDSCHMIDT; TAMIM; GOREN 1998).

Com relação ao desenvolvimento avaliado aos 60 e 120 dias após a aplicação do PBZ, observouse nas plantas submetidas à aplicação de $\mathrm{PBZ}$ via foliar redução de $63 \%$ e $31 \%$, no crescimento em altura e $39,8 \%$ e de $17,7 \%$ no diâmetro do caule, respectivamente, comparado-se as plantas pulverizadas com a concentração de $800 \mathrm{mg} \mathrm{L}^{-1}$ com as plantas não tratadas (Figuras 4A e 4B). Os resultados demonstraram que a ação do PBZ ocorre logo após a sua aplicação, pelo menos quando aplicado diretamente nas folhas, reduzindo seu efeito após um determinado período, cerca de quatro meses a sua aplicação, quando as plantas parecem retomar seu crescimento normal. Embora tenha sido verificada a paralisação no crescimento das plantas, a interferência não foi duradoura e provavelmente não tenha sido efetiva para alterar o balanço hormonal das plantas e influenciar na indução floral (KRAJEWSKI; RABE, 1995).

Quanto à aplicação do PBZ no solo, verificou-se que a redução no crescimento das plantas ocorreu de forma lenta, aos 120 dias foi verificada redução na altura $(42,8 \%)$ e no diâmetro do caule $(34,7 \%)$ nas plantas submetidas à dose de $8 \mathrm{~g}$ por planta, em relação às plantas do tratamento testemunha. Para a avaliação realizada aos 60 dias após a aplicação do PBZ, não houve diferenças entre as doses de PBZ aplicadas (Figuras 5A e 5B). 
Figura 4. Crescimento da altura de plantas (A) e diâmetro do caule (B) em oliveira (Olea europaea L.), aos 60 e 120 dias após a aplicação de paclobutrazol (PBZ) via foliar.

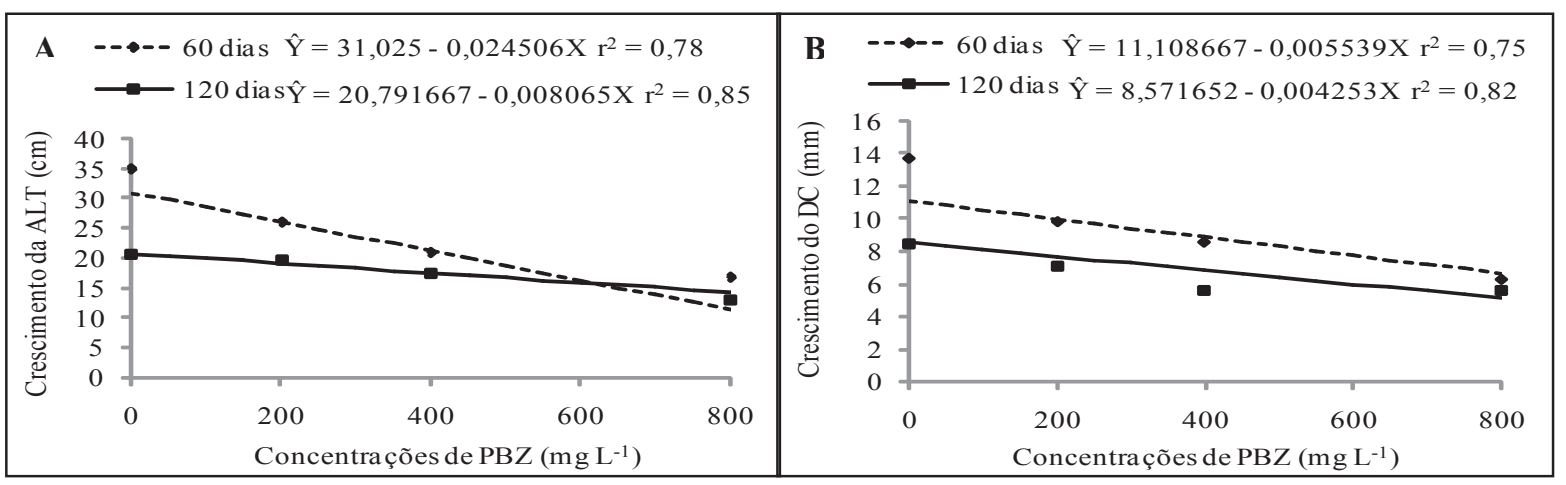

Fonte: Elaboração dos autores.

Figura 5. Crescimento da altura de plantas (A) e diâmetro do caule (B) em oliveira (Olea europaea L.), aos 60 e 120 dias após a aplicação de paclobutrazol (PBZ) via solo.

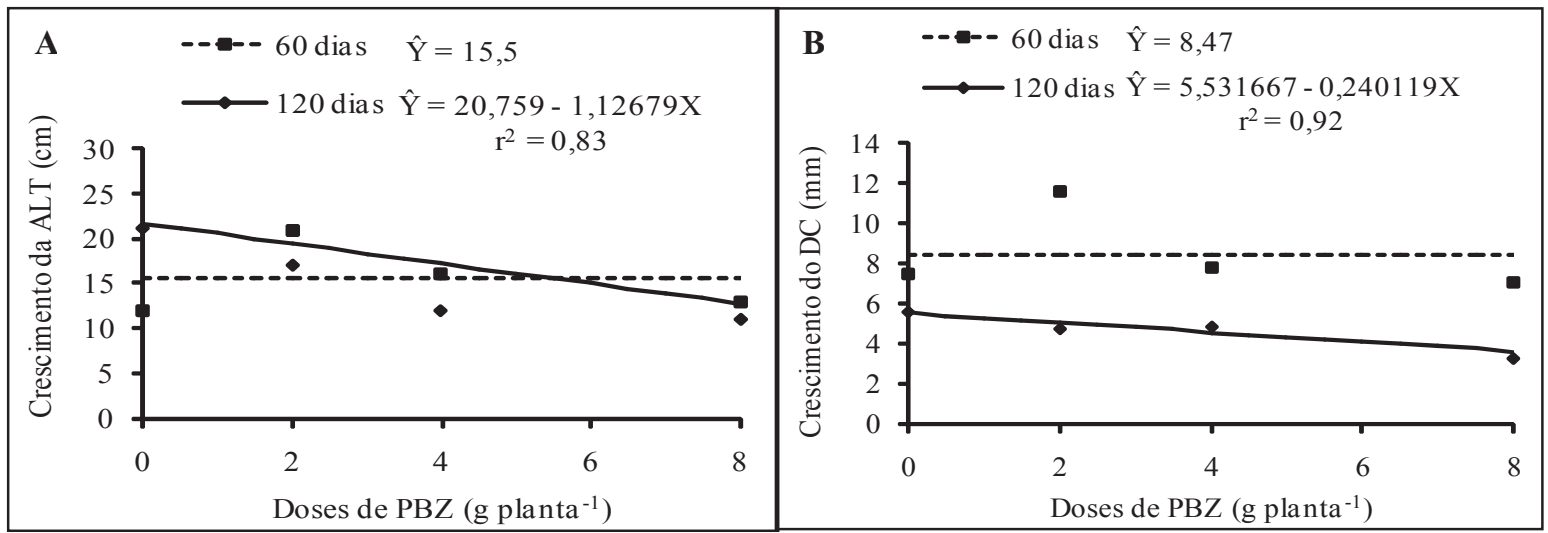

Fonte: Elaboração dos autores.

De acordo com Maganhotto, Fay; Vieira (2003), o PBZ é lentamente absorvido, quando aplicado no solo apresenta redução de 54,8 \%, aos 60 dias após, e posteriormente esta taxa mantém-se praticamente estabilizada. Além disso, pode haver interação com o meio, de modo que a sua absorção pela planta e a sua persistência no ambiente está relacionada ao tipo de solo e às condições climáticas (JACKSON; LINE; HASAN, 1996).

Com relação à restrição hídrica, foi observado aos 60 dias após a aplicação do PBZ via solo, maior crescimento nas plantas que foram irrigadas quando comparada com aquelas submetidas à restrição hídrica, para todas as doses de PBZ testadas. Aos 120 dias, apenas as plantas que não receberam a aplicação do PBZ e submetida à restrição hídrica apresentaram o menor crescimento (Tabela 1). Esse resultado sugere que possivelmente, quando o PBZ é aplicado no solo, a presença de umidade favorece o transporte e a ação do produto na planta.

Quanto ao comprimento de entrenós, foi observada redução linear à medida que se aumentou a concentração de PBZ aplicado via foliar (Figuras 6A). Nas plantas pulverizadas com a concentração de $800 \mathrm{mg} \mathrm{L}^{-1}$ de PBZ, a redução foi de 32,8\% comparadas às plantas do tratamento testemunha. 
Tabela 1. Crescimento da altura de plantas em oliveira (Olea europaea L.) submetida à restrição hídrica e aplicação de paclobutrazol (PBZ) via solo.

\begin{tabular}{|c|c|c|c|c|c|c|c|c|}
\hline \multirow{5}{*}{ Disponibilidade hídrica } & \multicolumn{8}{|c|}{ *Crescimento da altura $(\mathrm{cm})$} \\
\hline & \multicolumn{8}{|c|}{ Dias após a aplicação do PBZ } \\
\hline & \multicolumn{4}{|c|}{60} & \multicolumn{4}{|c|}{120} \\
\hline & 0 & 2 & 4 & 8 & 0 & 2 & 4 & 8 \\
\hline & \multicolumn{8}{|c|}{ PBZ $\left(\right.$ g planta $\left.^{-1}\right)$} \\
\hline Sem restrição hídrica & $13,8 \mathrm{a}$ & $24,16 \mathrm{a}$ & $20,3 \mathrm{a}$ & $16,8 \mathrm{a}$ & $36,6 \mathrm{a}$ & $7,3 \mathrm{a}$ & $7,5 b$ & $9,2 b$ \\
\hline Com restrição hídrica & $11,3 b$ & $18,6 b$ & $12,8 b$ & $11,3 \mathrm{~b}$ & $5,83 \mathrm{~b}$ & $7,7 \mathrm{a}$ & $17,5 \mathrm{a}$ & $13,3 \mathrm{a}$ \\
\hline $\mathrm{CV}(\%)$ & \multicolumn{4}{|c|}{30,71} & \multicolumn{4}{|c|}{28,46} \\
\hline
\end{tabular}

*Médias seguidas de mesmas letras na coluna, para cada dose, não diferem entre si a 5\% de probabilidade de erro pelo teste F. Fonte: Elaboração dos autores.

Figura 6. Comprimento de entrenós (CEN) em brotações de oliveira (Olea europaea L.) após a aplicação do paclobutrazol (PBZ) via foliar (A) e via solo (B).
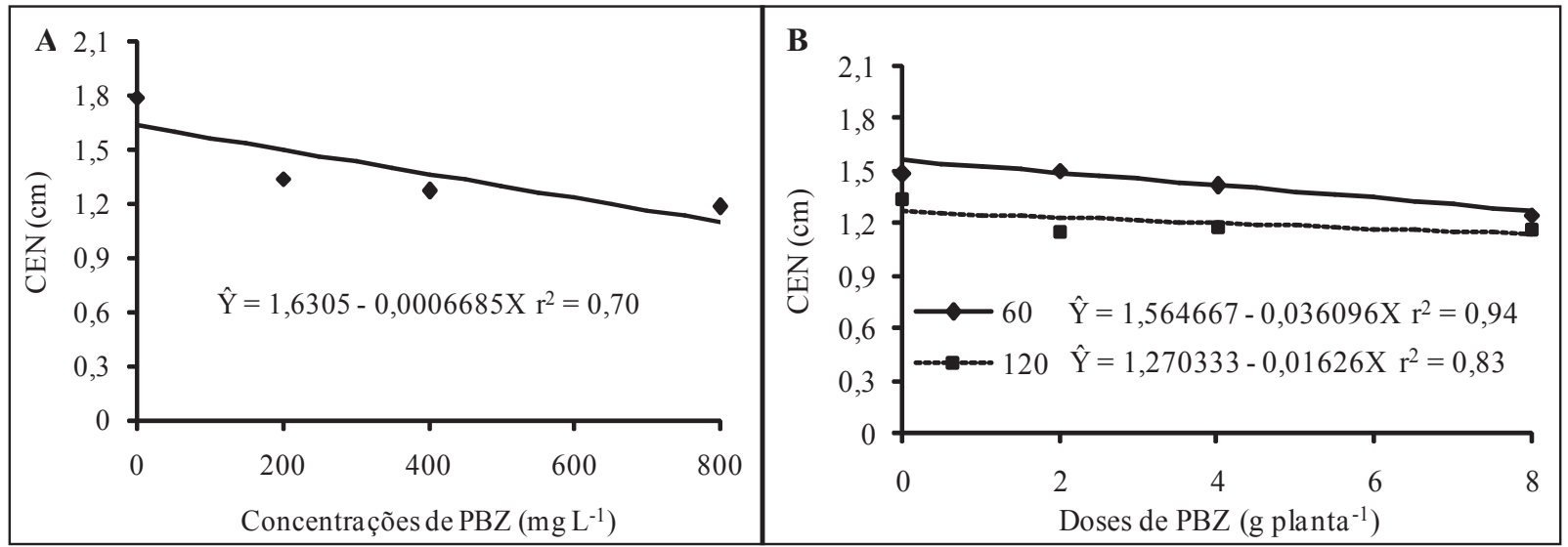

Fonte: Elaboração dos autores.

Comportamento semelhante foi observado em relação ao comprimento de entrenós, quando o PBZ foi aplicado via solo (Figuras 6B). Porém, houve diferença em relação à época, aos 60 dias após a aplicação o decréscimo foi de $18,45 \%$, e aos 120 dias 10,23\%, nas plantas tratadas com a $8 \mathrm{~g}$ em relação aquelas que não receberam aplicação de PBZ. Resultados semelhantes foram observados por Maganhotto, Fay e Vieira (2003) em relação ao tempo de resposta da planta ao PBZ aplicado via solo, sendo verificados efeitos expressivos na planta após 60 dias da aplicação, e a partir desse período seus efeitos tornaram-se menos intensos.

O potencial hídrico foliar $\left(\psi_{\mathrm{w}}\right)$ variou em função da época e da disponibilidade hídrica no solo que ocorreu no período de avaliação. Para as plantas que foram irrigadas os maiores valores de $\psi_{\mathrm{w}}$ ocorreram aos 64 dias após a aplicação do PBZ. Nas plantas que foram submetidas à restrição hídrica, o $\psi_{\mathrm{w}}$ decresceu de forma linear em função do período de avaliação, houve redução de 48,25\%, com valores de -1,18 MPa aos 120 dias após a aplicação do PBZ (Figura 7). Quando foi comparado o $\psi_{\mathrm{w}}$ das plantas nas diferentes épocas, observou-se que os menores valores ocorreram nas plantas submetidas à restrição hídrica após o início da aplicação dos tratamentos.

A variação observada em relação ao aumento do $\psi_{\mathrm{w}}$ nas plantas irrigadas até os 64 dias após o início dos tratamentos pode ser atribuída à ocorrência de baixas temperaturas, entre 14 e $15{ }^{\circ} \mathrm{C}$ nesse 
período (Figura 1A) que favoreceram a redução de evapotranspiração pelas plantas quando submetidas à irrigação. O comportamento das plantas que foram submetidas à restrição hídrica pode ser relacionado à baixa umidade no solo, em função dos baixos índices pluviométricos durante o período do estudo (Figura 1B).

Figura 7. Potencial hídrico $\left(\psi_{\mathrm{w}}\right)$ foliar em oliveira (Olea europaea L.), irrigada (sem RH) e submetida à restrição hídrica (com RH) em função do período de avaliação. As barras sobre as medias

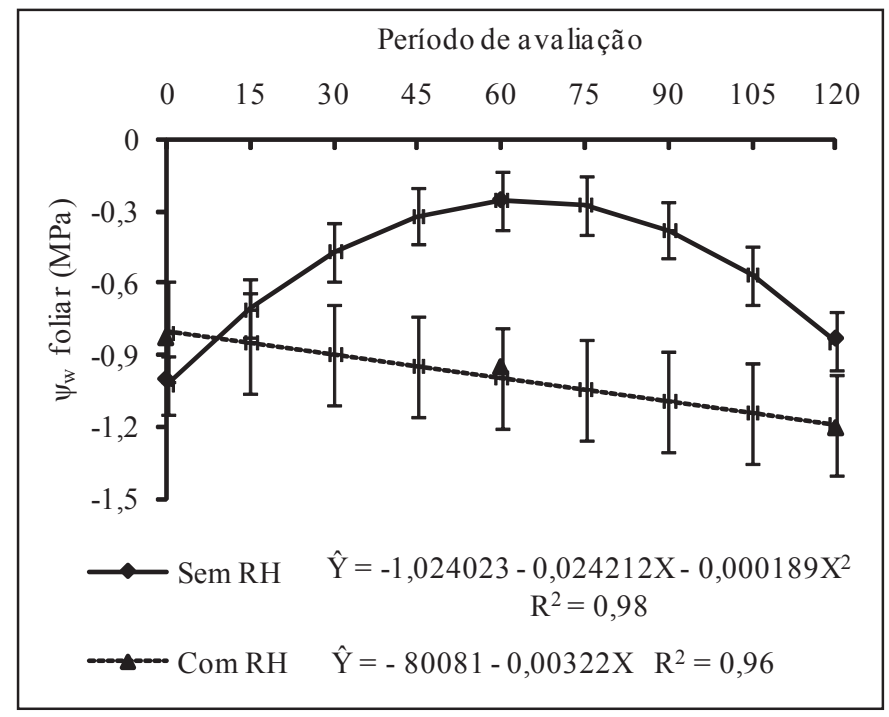

Fonte: Elaboração dos autores.

A diferença observada em relação aos maiores valores do $\psi_{\mathrm{w}}$ nas plantas irrigadas ocorreu devido à presença de umidade no solo (Figura 2A). Para estas plantas, o déficit de água no solo não ultrapassou -0,026 MPa, enquanto nas plantas submetidas à restrição hídrica, na profundidade de $0,2 \mathrm{~m}$, o déficit hídrico no solo atingiu valores em torno de $-0,1$ $\mathrm{MPa}$ e $-0,08 \mathrm{MPa}$ na profundidade de $0,4 \mathrm{~m}$, aos 120 dias após início dos tratamentos (Figura 2B).

A redução do $\psi_{\mathrm{w}}$ também foi constatada por Ahmed, Ben Rouina e Boukhriss (2007), avaliando os efeitos do déficit hídrico sobre a oliveira da cultivar Chemlali em condições áridas na região da Tunísia e por Rousseaux, Benedetti e Searles (2008) nas condições áridas da Argentina. Entretanto, nas condições do presente trabalho os valores determinados em relação ao potencial hídrico foliar evidenciam que a restrição de água não caracterizou uma condição de estresse considerada severa às plantas, que geralmente é alcançada quando o potencial hídrico foliar atinge valores em torno de -3,5 MPa a -4,0 MPa, necessária para diminuir a latência das gemas e, ou induzir a floração (DAVENPORT, 1990).

Com relação ao SPAD, foi observado aumento linear à medida que se elevou a dosagem de PBZ aplicada via solo e foliar às plantas. Para as plantas que receberam as maiores concentrações de $\mathrm{PBZ}$, houve acréscimo de $2,17 \%$ em relação às plantas do tratamento testemunha (Figura 8). Esse incremento, provavelmente, ocorreu em decorrência do menor desenvolvimento da área foliar das plantas tratadas com as maiores doses de PBZ.

Resultados semelhantes foram observados por Delgado, Rodriguez e Casamayor (1995) que constataram aumento nos valores SPAD das folhas em plantas de lima persa com a aplicação de PBZ. 
Figura 8. Estimativa de teor relativo de clorofila (SPAD), avaliada na face adaxial, em folhas de oliveira (Olea europaea L.) em função da aplicação do PBZ.

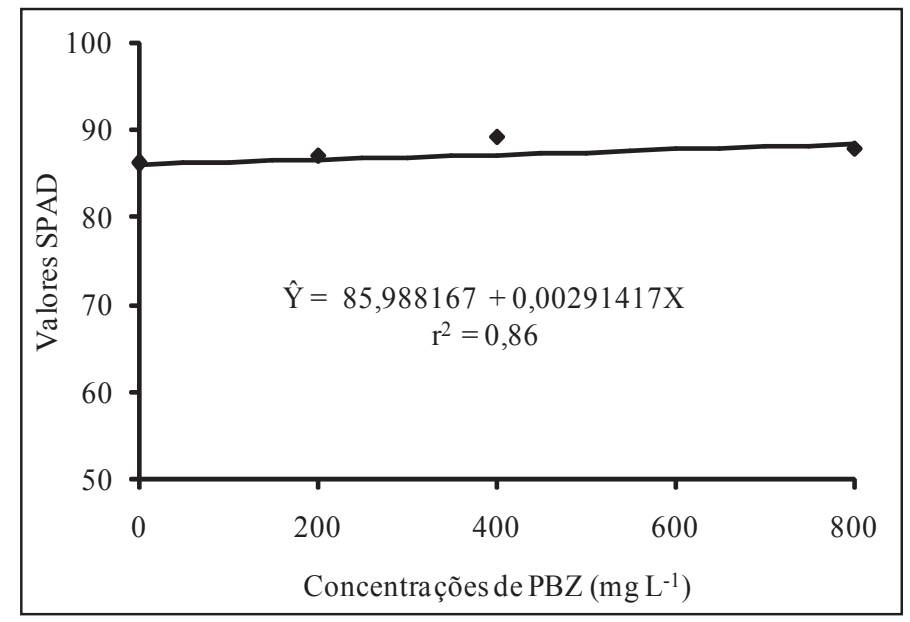

Fonte: Elaboração dos autores.

Foram observados os maiores valores SPAD nas plantas irrigadas quando comparadas com aquelas submetidas à RH (Tabela 2). A diferença do SPAD nas plantas submetidas à $\mathrm{RH}$ pode ter ocorrido em decorrência à baixa taxa fotossintética que reduz a quantidade deste pigmento sob estresses ambientais, entre eles o estresse hídrico, que tem sido relatado por outros pesquisadores (GUERFEL et al., 2009).

Tabela 2. Teor relativo de clorofila, valores determinados com o SPAD, na face adaxial de folhas de oliveira (Olea europaea L.) irrigada e submetida à restrição hídrica.

\begin{tabular}{cc}
\hline Disponibilidade hídrica & $*$ Teor relativo de clorofila (valores SPAD) \\
\hline Sem restrição hídrica & $89,49 \mathrm{a}$ \\
Com restrição hídrica & $85,69 \mathrm{~b}$ \\
\hline CV (\%) & 1,81 \\
\hline
\end{tabular}

*Médias seguidas de mesmas letras na coluna, não diferem entre si a 5\% de probabilidade de erro pelo teste $\mathrm{F}$.

Fonte: Elaboração dos autores.

Quanto ao florescimento das plantas, não foi observada a emissão de brotações floríferas, provavelmente porque as gemas permaneceram dormentes, observando-se que o crescimento vegetativo das plantas ocorreu a partirdos meristemas apicais dos fluxos de crescimento anteriores. Provavelmente porque as gemas não saíram da fase de ecodormência, ou seja, o desenvolvimento das gemas não aconteceu devido à condição climática da região. Pois, para que ocorra a iniciação floral da oliveira é necessário que a condição de latência das gemas seja modificada (RALLO; CUEVAS, 2008).
Para estes autores, as gemas localizadas nas axilas das folhas da oliveira podem ter destinos diferentes, algumas permanecem latentes ao longo da vida ou até que elas recebem um estímulo externo, outras têm um destino reprodutivo ou vegetativo, e outras simplesmente caem.

Nas condições em que foi conduzido este trabalho, a interação de fatores como as condições não indutivas ao florescimento, ou seja, ausência de baixas temperaturas e, ou de estresse hídrico no período que antecede a floração foram considerados 
limitantes ao estímulo à indução floral. O período de frio durante o estudo foi insuficiente, pois a oliveira requer um período com temperaturas entre 2 a $4{ }^{\circ} \mathrm{C}$ (mínima) e 15,5 a $19{ }^{\circ} \mathrm{C}$ (máxima) para o desenvolvimento de suas gemas florais (DENNEY; MCEACHERN, 1983) e o período de déficit hídrico não ocasionou uma condição de estresse as plantas alcançando valores moderados de potencial hídrico de $-1,18 \mathrm{MPa}$.

Os resultados obtidos neste trabalho evidenciam que a aplicação de fitorreguladores, retardantes do crescimento pode resultar em efeitos variáveis, quando aplicado em condições ambientais não são indutivas ao florescimento. Dessa forma o ideal é que seja realizado o zoneamento climático em função da cultivar e das condições climáticas de cada região para o estabelecimento da oliveira em novas regiões de cultivo.

\section{Conclusões}

O paclobutrazol foi efetivo para retardar o crescimento das plantas em ambas as formas aplicadas.

A paralisação do crescimento vegetativo nas plantas foi mais tardia quando o paclobutrazol foi aplicação via solo.

O déficit hídrico favoreceu a ação do paclobutrazol na planta quando aplicado via foliar e retardou quando a aplicação foi realizada no solo.

Não foi observado o florescimento da oliveira com a aplicação de paclobutrazol e déficit hídrico nas condições estudadas.

\section{Agradecimentos}

Ao Conselho Nacional de Desenvolvimento Científico e Tecnológico - CNPq, pela concessão de bolsa de estudo e da Fundação de Apoio à Pesquisa de Minas Gerais - FAPEMIG pelo auxílio financeiro.

\section{Referências}

AHMED, B.; BEN ROUINA, B. C.; BOUKHRISS, M. Effects of water deficit on olive trees cv. Chemlali under field conditions in arid region in Tunisia. Scientia Horticulturae, Amsterdam, v. 113, n. 3, p. 267-277, 2007.

CRUZ, M. C. M.; SIQUEIRA, D. L.; SALOMÃO, L. C. C.; CECON, P. R. Florescimento de limeira ácida Tahiti submetida a estresse hídrico e tratada com paclobutrazol. Cientifica, Jaboticabal, v. 37, n. 2, p. 53-60, 2009.

DAVENPORT, T. L. Citrus flowering. Horticultural Reviews, New York, v. 12, p. 349-408, 1990.

DELGADO, R.; RODRIGUEZ, R.; CASAMAYOR, R. Empleo de paclobutrazol em plantas de lima persa sobre naranjo trifoliado 'Rubdoux' a altas densidades. Agrícola Vergel, p. 121-125, 1995.

DENNEY, J. O.; MCEACHERN, G. R. An analysis of several climatic temperature variables dealing with olive reproduction. Journal of the American Society for Horticultural Science, Alexandria, v. 108, n. 4, p. 578$581,1983$.

FLETCHER, R. A.; GILLEY, A.; SANKLA, N.; DAVIS, T. D. Triazoles as plant growth regulators and stress protectants. Horticultural Reviews, New York, v. 24, p. 55-138, 2000.

GOLDSCHMIDT, E. E.; TAMIM, M.; GOREN, R. Gibberellins and flowering in citrus and other fruit trees. Acta Horticulturae, Leuven, v. 1, n. 463, p. 201-216, 1998.

GUERFEL, M.; BACCOURI, O.; BOUJNAH, D.; CHAÏBI, W.; ZARROUK, M. Impacts of water stress on gas exchange, water relations, chlorophyll content and leaf structure in the two main Tunisian olive (Olea europaea L.) cultivars. Scientia Horticulturae, Amsterdam, v. 119, n. 3, p. 257-263, 2009.

INTRIERI, C.; SILVESTRONI, O.; PONI, S. Preliminary experiments on paclobutrazol effects on potted grapevines (V. vinifera, cv.Trebbiano). Acta Horticulturae, Leuven, v. 2, n. 179 , p. 589-592, 1986.

JACKSON, M. B. Are plants hormones involved in root to shoot communication? In: CALLOW, A. J. (Ed.). Advanced in botanical research. New York: Academic Press, 1993. p. 103-187.

JACKSON, M. J.; LINE, M. A.; HASAN, O. Microbial degradation of a recalcitrant plant growth retardantpaclobutrazol (PP333). Soil Biology and Biochemistry, Oxford, v. 28, n. 9, p. 1265-1267, 1996. 
KRAJEWSKI, A. J.; RABE, E. Citrus flowering: A critical evaluation. Journal of Horticultural Science, Ashford, v. 70, n. 3, p. 357-375. 1995.

LEITE, G. H. P.; CRUSCIOL, C. A. C.; SILVA, M. A. Desenvolvimento e produtividade da cana-de-açúcar após aplicação de reguladores vegetais em meio de safra. Semina: Ciências Agrárias, Londrina, v. 32, n. 1, p. 129138, 2011.

MAGANHOTTO, C. M. S. S.; FAY, E. F.; VIEIRA, R. F. Degradação do paclobutrazol em solos tropicais. Pesquisa Agropecuária Brasileira, Brasília, v. 38, n. 10, p. 1223-1227, 2003.

MESQUITA, H. A.; FRÁGUAS, J. C.; PAULA, M. B. de. Adubação e nutrição de oliveira. Informe Agropecuário. Belo Horizonte, v. 27, n. 231 p. 68-72, 2006.

RADEMACHER, W. Growth retardants: effects on gibberellin biosyntesis and other metabolic pathways. Annual Review Plant Physiology and Plant Molecular Biology, Mineápolis, v. 51, p. 501-531, 2000.
RALLO, L.; CUEVAS, J. Fructificación y Producción. In: BARRANCO, D.; FERNÁNDEZ-ESCOBAR, R.; RALLO, L. (Ed.). El cultivo del olivo. 6. ed. Junta de Andaluzia: Mundi-Prensa, 2008. p. 626-662.

REYNOLDS, A. G.; WARDLE, D. A. Vegetative growth suppression by paclobutrazol in greenhouse-grown 'Pinot Noir' grapevines. HortScience, Alexandria, v. 25, n. 10, p. 1250-1254, 1990.

ROUSSEAUX, M. S.; BENEDETTI, J. P.; SEARLES, P. S. Leaf-level responses of olive trees (Olea europaea) to the suspension of irrigation during the winter in arid region of Argentina. Scientia Horticulturae, Amsterdam, v. 115, n. 2, p. 135-141, 2008.

SANTOS, C. H.; KLAR, A. E.; GRASSI FILHO, H.; RODRIGUES, J. D.; PIERRE, F. C. Indução do florescimento e crescimento de tangerineira 'Poncã' (Citrus reticulata Blanco) em função da irrigação e da aplicação de paclobutrazol. Revista Brasileira de Fruticultura, Cruz das Almas, v. 26, n. 1, p. 8-12, 2004. 